\title{
Measured as the water flows: the striated and smooth in marine spatial planning
}

\author{
Stephen Jay ${ }^{1}$
}

Received: 29 April 2019 / Accepted: 30 October 2019 / Published online: 13 December 2019

(C) The Author(s) 2019

\begin{abstract}
Marine spatial planning (MSP) now has a sufficient history for consideration of the way in which MSP processes are developing over time, gaining experience and responding to issues that arise. Rather than setting a study of this kind in the well-established framework of adaptive management, I choose instead a spatial concept that allows planning action to be more closely meshed with the nature of the marine setting itself, that of Deleuze and Guatarri's notion of striated and smooth spaces. This suggests that there are two different manners in which space is produced, which are interdependent and interchanging and work together in making progress; this has certain resonances with the materiality of the sea. I use this concept in a reading of an MSP process with a relatively long pedigree, that of the Shetland Islands, Scotland, UK, focusing particularly on the development of aquaculture policy, through analysis of a sequence of documents. The study reveals that policy-making is suffused with striated and smooth spatialities, finding expression on the one hand in development criteria and other regulations, and on the other hand, in discretion, negotiation and opportunity-building, with the two yielding to each other and advancing together with their different types of movement. This suggests a more general manner by which MSP processes may progress, by spatial dialectic of this kind, in which those who practice MSP engage through their own reasoning of the natural and human structures and dynamisms of the coasts and seas and their responsive plan-making.
\end{abstract}

Keywords Marine spatial planning $\cdot$ Deleuze and Guatarri $\cdot$ Striated and smooth space $\cdot$ Shetland Islands $\cdot$ Aquaculture

\section{Introduction}

Marine spatial planning (MSP) now has a history. In some areas, a sequence of plans has been produced through an ongoing MSP process (Blau and Green 2015), inviting exploration of the changes that have taken place during these processes, especially the ways in which the planning response to perceived issues may have developed. For example, how have successive plans reflected growing knowledge of environmental conditions and human demands? And how has the experience of one round of planning efforts informed the next? A genealogy of plans would be a fruitful dataset for studying an MSP authority's evolving understanding of its means of intervening in the marine activities and interests in its area. This could contribute to our wider understanding of

Stephen Jay

stephen.jay@liverpool.ac.uk

1 Department of Geography \& Planning, University of Liverpool, Liverpool L69 7ZT, UK the directions being taken by MSP as a whole as experience is gained. It could also contribute to efforts to make MSP practice more responsive to its setting (Jay 2012), if indeed evidence emerges of MSP progressing in this sense.

A study of this kind could be set in the well-established framework of adaptive management. This is the argument that an MSP cycle should culminate in a review of the process undertaken, supported by monitoring, leading to an evaluation of the effectiveness of the plan, with lessons learned and changes proposed for the next iteration of plan-making (Day 2008; Douvere and Ehler 2011; Ehler 2014). However, this model focuses on the procedures required rather than the nature of the marine setting involved. An adaptive response may be triggered by the behaviour of the setting, the consequences of planning efforts upon it, or the failure to achieve intended outcomes. But this is essentially a reactive response, in which the measures are defined by the tenets of resource management rather than emerging from the shifting substance of the sea, its multifarious inhabitants and non-material qualities. These are somewhat distanced, treated as the object of institutional intervention. A more embodied approach might be expected, whereby planning action, and how it 
is conceived, is more closely meshed with the nature of the marine setting itself. Again, this could help in developing MSP approaches that are more attuned to the activities that they are seeking to support.

So I turn instead to a body of thought which holds out the possibility of immersing planning action in its setting. This can be described as a spatial theory or concept. Importantly, 'spatial' here is understood not simply in terms of envirophysical, but also socio-institutional, dimensions. The spatial incorporates both the physical arrangements of activities and the social processes that shape those arrangements. The two are intertwined; for example, in the context of strategic (landbased) planning, joined-up forms of governance can produce cross-sectoral solutions on the ground, further reinforcing institutional integration for the sectors concerned (Haughton et al. 2010). I therefore use the term 'spatial' in a way that already seeks to overcome the dichotomy between the process and object of planning referred to above, leading to a more synergistic relationship between the two.

The spatial concept chosen for this exploration is that of striated and smooth space, as developed by Deleuze and Guatarri, in their seminal work, A Thousand Plateaus (1988). This is for three reasons. Firstly, their perspective offers an ontological fusion between process and object, or form, thus supporting an expanded understanding of the spatial, as suggested above. This is despite the physical connotations of the metaphors used (striated and smooth), as there is as much emphasis on inner powers as on outward shape, and these are inextricably bound together, and embody movement and progression. Secondly, this liveliness echoes many of the characteristics of the marine environment, which MSP might seek to relate to more closely in its own practices; processform fusion is thus taken into fluid and mobile territory. Thirdly, the notion proposes continual and necessary interchange between its two spatial types, which has the potential to connect with the underlying concerns of adaptive management, as the dynamic of switching between types may provide a (ontologically unified) logic of responding to outcomes as they arise.

Below, I begin by exploring the concept of striated and smooth space itself and its resonance with MSP and related fields. Then I turn to an empirical study of an MSP process, in which I explore the potential for this framework to help describe its progression. The MSP process chosen is one of those referred to above that have a history of several iterations, namely for the Shetland Islands, Scotland, UK. One aspect of the process is studied in more depth, that relating to aquaculture, because of its particular resonance with the chosen concept. I then reflect further on the results of this exploration and its value to our wider understanding of how MSP processes are evolving, and indeed what it may have to offer to understanding of the striated-smooth model.

\section{Striated and smooth spaces}

Deleuze and Guatarri's work has been described as a geophilosophy, offering perspectives on the complex physical, organic and social relations that infuse the world (Bonta and Protevi 2004). A Thousand Plateaus (Deleuze and Guatarri 1988) presents a sequence of such perspectives. Accepting the invitation of the translator (Massumi) to 'lift a dynamism' from this book and incarnate it elsewhere (xv), I have selected the final chapter dealing with striated and smooth space and sought to graft into it the dynamism of MSP and its settings. This text appeals no doubt because of its overtly spatial dimension, which has already drawn attention from the spatial disciplines (especially architecture and geography, with some interest from planning (e.g. Abrahams 2017; Dovey and Polakit 2010; Hillier 2007; Livesey 2010; Purcell 2013)). More particularly, even with a superficial reading, the text speaks directly to questions being raised within planning thought, where tensions between conventional methods of planning (striated?) and dynamic planning contexts (smooth?) continue to perplex, not least in the marine realm (Allmendinger et al. 2015; Jay 2012). There is also the specific appeal of the chapter's maritime model and its presaging of issues now being encountered in marine governance. In reading this text, therefore, I seek to create meaning for the practice of MSP; I do this by bringing existing, and perhaps new, perspectives from MSP into my explorations on some of these plateaus.

The authors set out an apparent opposition between the striated and the smooth, described as nothing less than a 'primordial duality' ( $p$ 496). This is expressed through various 'models' in which the two are repeatedly set alongside each other. The first is the technological model, which consists of different kinds of cloth: striated weaved fabric on the one hand, and smooth felt on the other. The former is constituted of ordered, interlaced vertical and horizontal threads, necessarily fabricated within a fixed, closed frame. The latter is a rolled entanglement of fibres, producing a closely textured surface, varying but without geometric pattern, extendable without limit. We need go no further in finding resonances with the planned and the unplanned; functions located, bounded and arranged within the confines of a plan (following the authors' own socio-political correlation here, of state government as a form of weaving) versus the freely spreading and jostling spatial happenings of an unregulated land. Developing a planning model in this way takes us straight to its marine variant, where the smooth is even more starkly present in the unplanned, and hitherto unplannable, sea (Jay 2010). This is explicitly described in Deleuze and Guatarri's maritime model as smooth space par excellence ( $p 479$ ), the archetype of smooth space ( $\mathrm{p} 480$ ), smoothness so primordial and in the blood that, despite being central to the model in question, it requires no further explanation. Hence Hillier's endeavour of a Deleuzianinspired terrestrial planning practice takes the sea as a baseline of smoothness, 'in continuous variation, composed of subtly shifting tactile qualities' (2007, p 168). 
Other insights follow, illustrating the two different manners of working. For example, in another model, the musical one, metric striation, in which quantifiable elements succeed each other, is contrasted with nonmetric smoothness, in which there is continuous development and fusion. Similarly in the mathematical model, a distinction is drawn between numerically divisible or multipliable units, where the divided is a sub-part of the unit, and dimensions that change in nature over their range, such as temperature, which is characterised by differences of intensity. Again, striation brings planning to mind, at least the extreme of Euclidean zoning (Haar and Kayden 1989), with its emplacement and accumulation of defined, bounded uses. This is an approach that many within MSP circles are assuming to be the planning norm and are attempting, in an act of metric replication, to put into practice in the marine realm (Agardy 2010; Jay 2013). But smoother variations and step changes also find their place in planning. For instance, as the multiple scales of planning are traversed, climbing from the local and unitised, horizons become wider, more cross-cutting considerations come into play, and solutions are different in kind to those for the parts, being more provisional in nature and yet more ambitious (Healey 2004). Hints of similar dimensional and conceptual shifts are evident in MSP, with, for example, the abandonment of precise coordinates for fixing activities in favour of more discursive and representational approaches to using the sea's resources, especially at higher geographical levels (UNEP and GEF-STAP 2014).

Movement is integral to and constitutive of the spaces. For example, variation in the mathematically smooth is likened to the transitions between walking and trotting and galloping. The striated and the smooth can be differentiated by the manner of one's crossing: either going from point to point and organising with progression, or moving along vectors and distributing as one travels. But this is not just a matter of moving in a striated or smooth manner through space; it is about producing (different kinds of) space through movement. So in the aesthetic model, spaces are actively produced through art, by drawing either the striated line of orientation and perspective or the smooth line of abstraction and expression. The planner's hand seems predisposed to the former, in designating land use and setting the terms of development, represented geometrically and textually. But as Lefebvre (1991) has shown, urban space is produced not just through these technical means but also via daily practices and cultural expressions, and herein lies the opportunity for smoother wanderings in search of urban realities and imaginings (Soja 1996).

Interestingly, it is movement across the sea that holds a defining moment in the history of striation, when in 1440 (this is the seminal date referred to by Deleuze and Guatarri in the chapter's heading) nautical charts began to take shape and impose a grid pattern upon the waves (Lysen and Pisters 2012). MSP continues to aid voyagers and sea users by filling the grid with data, policy and licences, with GIS-generated maps being the preferred method of inscription and territorialisation (Knol 2011). But some actors continue to resist channelling and insertion into coordinates, such as ecologists explaining the fluctuating meanderings of mobile species and fishers defending their need and their right to roam freely in search of their prey (English Nature 2003; Jay et al. 2012). Even the deeply inscribed may continually give way to countervailing forces. For example, the passage of ships on set routes is no more than an occasional interruption on the surface of the deep, as their cutting wake is soon smoothed over by the intersecting waves. The solidly mapped shipping lanes are vulnerable to the accusation of facade.

This last observation points to the interchangeability and interdependency of the striated and smooth. Rather than being separable opposites as initially implied, they must co-exist and affect each other, one mutating into the other, only for the transformation to be reversed and progressed. So at the heart of music, there is communication between, and melding and creative accumulation of, harmony and rhythm. Even the apparent permanence of different kinds of cloth has histories of emanation, with striated embroidery evolving into smooth patchwork. In terms more familiar to the geographically alert, the simple dichotomy of the ordered town and the open countryside is compromised by the knowledge that the land-tied ways of the town were adopted by formerly migratory cultivators, fixing agricultural practice just as strongly as street patterns. We might now see this exchange expressed in the ambiguities of the peri-urban, where opportunistically situated and operated land-uses are encroached upon and shaped by the stricter forms and rules of the city (McGregor et al. 2006). Returning to the original text, the striated and the smooth are in constant interplay even within fixed categories, with, for example, the settled cultivator still exposed to the freely moving wind.

This leads to the question of preference. It might be expected that smooth space is preferred to striated, especially from a wider Deleuzian perspective that privileges frictionless trajectories over halting introspection, becoming over being (DeLanda 2002). We may well be drawn to the radical, liberating alternative offered here, especially when the striated is associated with authoritarian control of resources (e.g. Hillier 2007, p 130), or with the bureaucratic parcelling of land, as I suggest above. Indeed, Deleuze and Guatarri just occasionally seem to look more approvingly on the smooth (where, after all, 'all becoming occurs' ( $p$ 486)), as in the work model, where the striated involves the disciplining and dividing of previously free rhythms of life into labour and its derivatives. But judgement is generally set aside; the project is principally to describe the continual squaring up, embracing, yielding and metamorphosing of these two poles.

However, the fundamental differences between the two mean that they do not act upon each other in the same manner: 'they bring dissymmetrical movements into play' ( $p$ 478). It is in the nature of striated space to take over smooth space by organisation, incrementally, the smoothness passive and enveloped; smooth space may even 
invite striation, requiring form and definition. It is in the nature of smooth space to gain and grow, to appear within and beyond striated space; striated space may collapse into smoothness, or emanate it from within. So different forces are at work in the oscillation between the two. For example, the striation of the sea by inscribed navigational lines may be reversed by the nomadic manoeuvring of submarines, reasserting the sea's spreading essence. The oppositely situated city ('striated space par excellence' ( $p$ 481)) is equally but differently susceptible to mutation, as it may, for example, generate the smoothness of a disordered shantytown by its own urbanising logic, which may in turn develop a more ordered form. One prepares for and inspires the other. There is the suggestion of mutual need, not simply of symbiotic co-existence, but of rotating expressions, where each transformation is formative and enlivening.

This implies that if there is preference, a spatial ambition, it is found in the co-dependent whole, where the creative energy and driving onwards of the striated and smooth are in permanent exchange, each bringing its own mechanisms and outcomes to bear. So even if 'all becoming occurs in smooth space', this is equalled by 'all progress is made by and in striated space' ( $p$ 486). For planners, the co-generation of becoming and progress could be constructive, not separated into different practices (as implied in Hillier's (2010) suggestion that strategic planning has the potential to be imaginative (smooth), while localised planning represents the fixed (striated)), but intertwined in every practice. Terrestrial and marine planners might work within their respective archetypes of city and sea with practices of both visionary becoming and detailed progress at every level, advancing through alternating emphases of one over the other, one producing the other in a necessary evolution of the whole, the leap-frogging of experimental concept and measured execution.

But do we then speak not of two spaces, but just one? One lively space (Jay 2018) composed of the striated and smooth as coupled, interchangeable phases? For this to be meaningful, the striated and smooth have to be understood as temporally and physically productive. They are generative processes working towards their composed forms (in two different ways); they are unified process-forms, implicitly temporal as well as material (Massey 2005); process = changing form, both within the production and furtherance of the smooth or striated, and in the transition from one to the other. So two types of spatial entity are in continual production and interchange, and their markedly different fashions of operation are necessary to the perpetuation of the whole. Hence this space is self-sufficient, holding within itself its own productive mechanisms.

\section{Sensing the striated and the smooth in marine spatial planning}

Interpreting space and spatial practice in the Deleuzoguatarrian terms described above requires reflection on one's own relation to this spatiality. A starting point is to recognise that the act of interpretation may itself be one of striation, as spatial categories are invented and distinctions are drawn between this practice and that. But countervailing smooth descriptive language may also be attempted. This recognition removes any doubt that interpretation is immersive; it is to join in spatial endeavour and becoming. Furthermore, to draw the attention of actors to new understandings is to invite reflection on their part and suggest alternative ways of working. The conviction is therefore political as well as analytical to adopt an interpretive stance that embodies the ontological fullness of the matter in hand. Exploring striated and smooth dynamics within an MSP process should therefore begin with the same kind of dynamics in one's own spatial thinking, extending the sense of spatiality to cognitive reasoning. This can be further nurtured by what is experienced through the research, not least with the material and social happenings of the marine world. This may then lead, in a political act, to encouraging others to exercise this way of thinking.

My manner of investigation is thus to search for occurrences of the smooth and the striated and the interchanges between them, as informed by my reading of the text above. This is with regard to the material and institutional realities in which those involved in MSP operate, reflecting a less humancentred understanding of the world, not least the marine environment (Anderson and Peters 2014). I do this via a study of a particular MSP process, for the Shetland Islands, as this allows the possibility of these dynamics to be uncovered. This is with an emphasis on specifics, but also with an eye to broader understandings that may emerge (Stake 1998).

This process was chosen because of the genealogy of documents generated over a period of a decade or more, in line with the area of interest traced out in the opening paragraph of this article. In fact, the Shetland Islands have one of the longest running MSP processes in Europe. But rather than attempting to study the whole range of issues covered by these documents, my study focuses on the topic of finfish and shellfish aquaculture. This is partly because aquaculture is a central and growing concern within this MSP process, and partly because it lends itself well to the approach outlined above, as indications of smooth and striated spatiality are immediately apparent in its treatment within the process.

The method of inquiry used in this study is documentary analysis. The sequence of the main public documents produced during the course of the MSP process, from 2007 to 2014, was studied, with a view to lifting out instances of the striated and smooth in the aquaculture sections. They were examined for the policy positions expressed through the text, through detailed scrutiny of the wording and consideration of 
the possible 'fit' of each statement to the striated or smooth. The graphics were also considered in a similar way. This method was applied consistently across the body of documents (Bowen 2009). Analysis thus consisted of a theoretically informed reading and interpretation of the text (May 2011, p 211).

\section{The Shetland MSP process}

The evolution of the MSP process for the Shetland Islands (also referred to simply as Shetland) has been well documented by Kelly et al. (2014). It began in 2006 with a pilot project, one of a set of projects carried out in Scottish waters (Scottish Sustainable Marine Environment Initiative (SSMEI)) (Scottish Government 2008). This reflected early policy interest in MSP in Scotland as a whole (Slater 2004; Tyldesley 2004). The Shetland pilot was one of the more successful projects, leading to a non-statutory plan for the whole of the islands' marine (internal and territorial) waters in 2008. Uniquely in the UK, the local authority for the area, Shetland Islands Council (SIC), has historic jurisdiction over its marine hinterland. This is because it was given offshore planning powers in the 1970s in connection with a major North Sea oil and gas terminal on the islands (Kelly et al. 2014)); it has also used these powers since the 1980s to issue licences for fish farms. So the council took a keen interest in the MSP process. A scientific institute based in Shetland, the NAFC Marine Centre, took the lead in producing the plan, working closely with the council.

The 2008 plan was revised twice, leading to new 'editions' in 2009 and 2010 (Hull 2013). The second was a relatively modest update, while the third was a more substantial reworking. A breakthrough occurred with the 2014 fourth edition, which was more comprehensive and was formally adopted by the council as 'supplementary planning guidance' (i.e. supplementary to the main spatial plan for the islands). This gave it statutory weight, enabling it to play a more determining role in planning decisions relating to offshore activities.

There is therefore a sequence of four main documents. This stepped progression was further punctuated by draft versions for some editions, put out for public consultation. Flowing through this process are the evolving aims, policies and actions for key themes, including for aquaculture development, which figures prominently throughout. In addition, the provisions for aquaculture draw on interim policy that predates the MSP process. These documents are, for convenience, referred to below as follows:

- Interim Aquaculture Policy (SIC 2007; also appendix 5 of Edition 1)

- Edition 1 (SSMEI 2008)

- Edition 2 (SSMEI 2009)
- $\quad$ Edition 3 (NAFC Marine Centre 2010)

- $\quad$ Edition 4 (SIC 2014b) ${ }^{1}$

The documents contain information about the aquaculture industry in Shetland, including maps, and policies setting out how the industry should be supported. The documents also set out environmental and other conditions which are likely to constrain aquaculture development. (Progress is now being made on a new plan, under the terms of national MSP legislation (Scottish Government online). However, this falls outside the scope of this study.)

\section{The spatiality of Shetland's aquaculture policy}

Marine aquaculture is a growing industry in Shetland. Finfish (mostly salmon) are raised and shellfish (mostly mussels) cultivated in relatively small-scale operations in the many inlets (known as 'voes') and straits around the islands. These stretches of water, many of which are long and narrow, offer sheltered conditions and ample circulation of clear Atlantic water. The industry's importance to the Shetland economy is stressed in the plan; for example, Edition 4 states that it supports several hundred direct and indirect jobs and produces; elsewhere it is stated that it produces 'over 30\% of Scotland's farmed salmon' and ' $69 \%$ of Scotland's farmed mussels' (SIC 2014b, p 129). Moreover, production has increased significantly over the last two decades, as much as fourfold in the case of finfish (SIC 2014a, 2017). There are approximately 250 sites in total. The industry is privately owned, mostly in the hands of a small number of operators with wider Scottish or North Sea interests. They were jointly represented in the MSP process via 'Shetland Aquaculture' (SIC 2014b).

Both forms of aquaculture introduce hard structures into the water, very visible pieces of equipment floating on the surface. In the case of salmon, these are circular frames supporting underwater enclosed nets, and in the case of mussels, large barrel-like buoys from which ropes hang, colonised by the mussels. Moreover, these are geometrically arranged: sets of circular pens arranged together or long, parallel lines of buoys chained together, along with moorings for boats (Figs. 1 and 2). One can easily perceive striated physical forms and their incremental progression as the industry grows, not least as they extend outwards from the shoreline, the contour of which they measure themselves against, imposing solid frameworks on the shifting water. Below the surface, too, objects evenly take their place, nets and ropes, to be populated by equally bounded and distributed organisms. Here, however, countervailing fluidity operates, as currents, tides and the

\footnotetext{
${ }^{1}$ It should be noted that a 5 th edition was being prepared during the time of this analysis.
} 


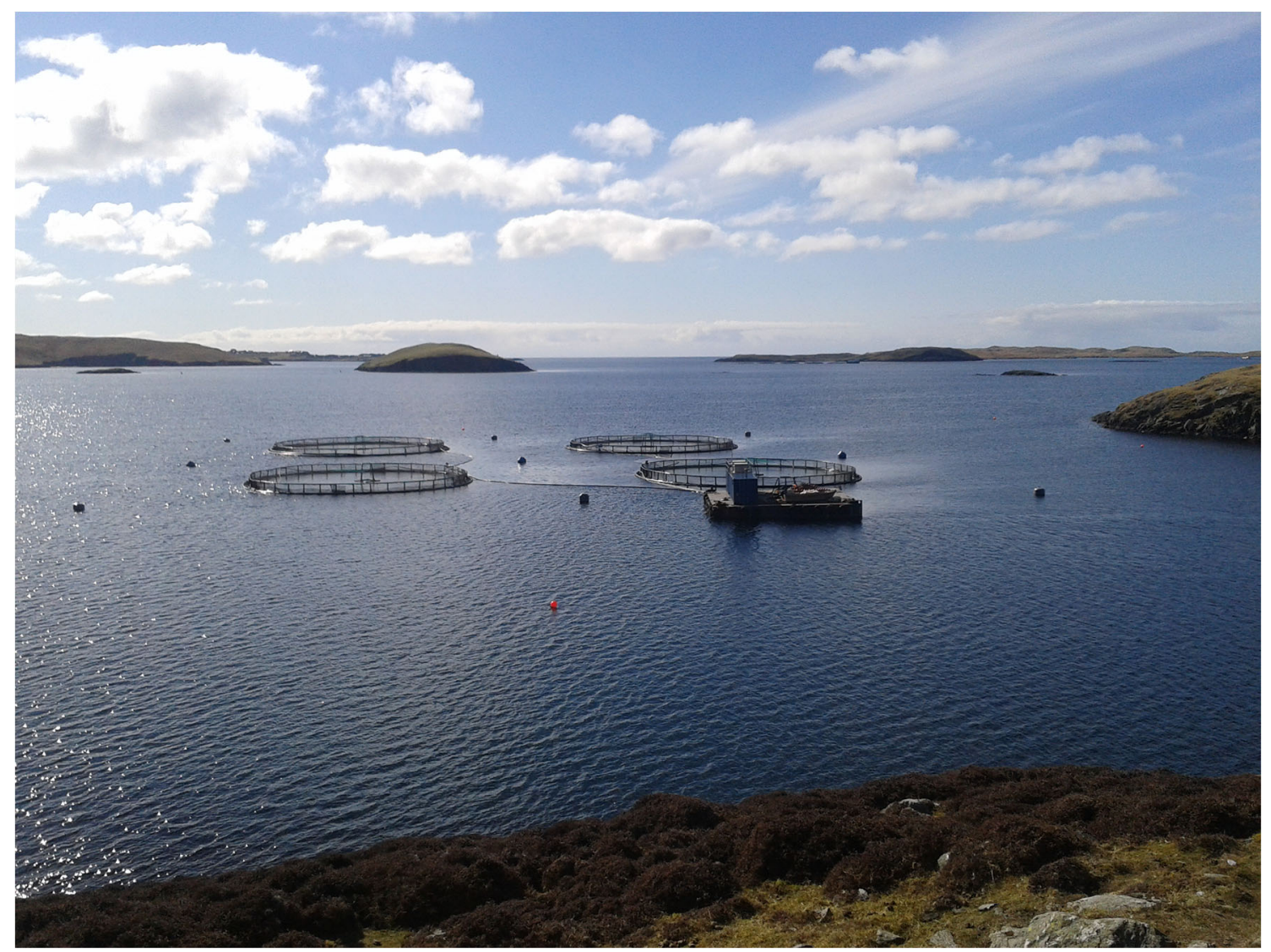

Fig. 1 Finfish aquaculture in Shetland (courtesy of Rachel Schucksmith)

weather impose their smoothly moving force, shifting the objects about, supplying and circulating food and nutrients and flushing away waste materials, in a necessary symbiosis of different manners of movement and occupancy.

The intervention of the MSP process began, as mentioned above, by drawing on Interim Aquaculture Policy. This sets out the issues that should be considered when determining applications for new aquaculture sites. These include the following: allowing for safe navigation in nearby waters; potential environmental impacts; existing nearby fish farms; and infrastructure needs. Some of these matters are expressed in quantitative terms. For instance, maximum parameters are set down for equipment such as finfish cages, which must not have a surface area of more than $9000 \mathrm{~m}^{2}$; and new finfish developments must be at least $1000 \mathrm{~m}$ away from existing finfish farms, or $500 \mathrm{~m}$ from shellfish farms. Intriguingly however, distances are sometimes described not in usual terms, but, for example, as ' $1000 \mathrm{~m}$ measured as the water flows', so that distance varies with the direction, or possibly speed, of flow. In this phrase, striated intervals of distance are invaded by smoothly running forces, and the two become enmeshed. This is perhaps the most succinct example of the interweaving of the two spatial types in these documents, hence my use of this term in the title of this article.
Other varying considerations come into play in the Interim Aquaculture Policy, such as codes of practice that may be adopted, or potential environmental effects, which require more nuanced judgement. And the numerical rules may be overtaken by smoother reasoning, so that minimum distances may be waived if water treatment conditions allow or increased for environmental protection reasons. Conversely, rules may impose themselves afresh, such as strict limits on the capacity of equipment for new or novel species. The interchange of 'musts' and 'mays', of prescription and discretion, reflect the shifting fortunes of quantitative and qualitative reasoning, one giving way to the other, each calling upon the other to modify as necessary, either by new rules stepping in from outside (striated) or reflective reasoning pushing up from within (smooth). It is as if the inadequacies of one approach alone are addressed by the other; for example, the risk inherent in allowing too much latitude in considering new sites is reduced by introducing clear-cut rules, but blind enforcement of rules is avoided by still allowing for judgement.

So interplay is evident within this foundation layer of aquaculture policy in Shetland, as if to mimic that of the industry's physicality, that of solid objects interacting with flowing water. The same forces continue to be at work as the plan proceeds. Edition 1 includes an aquaculture section. This refers to 


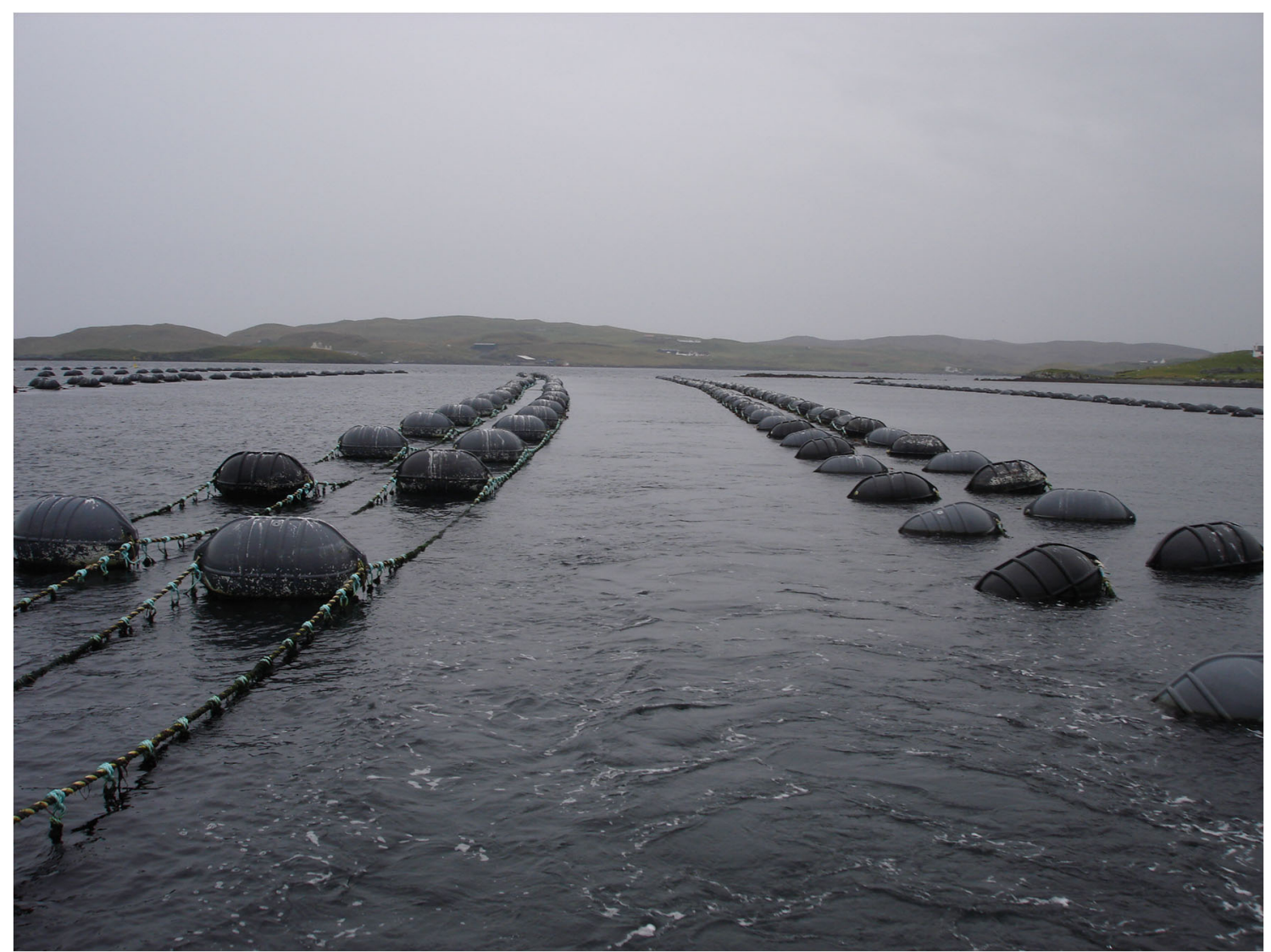

Fig. 2 Shellfish aquaculutre in Shetland (courtesy of Richard Shelmerdine)

the Interim Aquaculture Policy as the basis for determining applications for fish farm development (either new or modified sites). But it also refers to a suite of other policy documents, such as national planning guidance and European conservation legislation, and to regulatory instruments, such as environmental impact assessment requirements. The importance of public consultation and conflict resolution is also stressed. These introduce a greater demand for being led by scientific evidence on the one hand and other considerations on the other, with their respective inferences of striated and smooth thinking.

Similarly, the section includes a formal policy (simply entitled 'Aquaculture', presented prominently in a box). This stresses the need for development to conform to the plan's overarching concerns for nature conservation, other economic activities, communities and so on. This is done via crossreference to the general policies of Edition 1, which express broad principles often leading to the imposition of stricter conditions. For example, the principle of sound stewardship of wildlife is followed by an insistence that significant adverse effects on protected species would not be permitted. And even within the wording of the aquaculture policy, discretion and rule-making rub shoulders; so whereas the council 'may be minded' to refuse even applications that respect separation distances, it is then stated 'for the avoidance of doubt' that monofilament nets are not permitted for preventing predation of stock. Overall, the section sets the stage for decision-making, with many possible interventions from wider policy frameworks, material realities and groups. But their smoothly moving operation frequently comes up against or morphs into hard, definitive statements, as if open-ended reasoning by itself is not enough. Indeed, the overall purpose of the policy is stated as clarifying conditions that 'restrict' aquaculture development; some textual striations are needed to impose physical limits. Such interaction produces a more lively policy environment that would be produced by just one or the other approach, one that is more attuned to the variation and changeability of the physical setting that it seeks to engage with.

The aquaculture section of Edition 2 differs little from that of Edition 1. The only change (apart from updated policy framework references) is more precision on the basis of 'locational guidelines' for finfish sites. It is stated that these were determined using predictive models of nutrient loading.

Edition 3 expands the aquaculture section considerably. The inherited policy is now entitled 'Aquaculture: key conditions', and three new policies are added, all focusing on avoiding over- 
development. The first new policy encourages area-wide management plans that would improve conditions generally; this includes, for instance, greater separation distances and reduced impact on the environment and other activities. The second reasserts the minimum separation distances between sites; but this striation is open to smooth reconsideration if it can be demonstrated that lesser distances would bring benefits without an increased risk of disease transmission. And the third deals with the Swarbacks Minn area, which is already under pressure from aquaculture activity, prohibiting further development, except under certain conditions. (However, this policy did not survive a later revision of Edition 3, suggesting a re-think of such a strict limitation.) The other significant addition in Edition 3 is clarifying 'local policy restrictions' (referred to in the previous editions without explanation); these also refer to areas where aquaculture will not be permitted, either because capacity has been reached or because of proximity to the Sullom Voe oil terminal.

The overall impression is therefore one of growing confidence in controlling the growth of aquaculture, particularly through the use of physically defined restrictions, but also by expecting the industry to set out measures for improved environmental performance and greater socio-economic benefit. At the same time, the geometry is open to negotiation in some instances; indeed, some planning considerations, such as management proposals, require smoother interventions in the form of more discursive deliberation.

Edition 4, as a whole, represents an organised step up: it is linked to the local development plan (the statutory plan for Shetland as a whole) as 'supplementary guidance', finally achieving formal status in planning decisions. Along with this, the structure and format are a clear shift away from the previous editions. For instance, the aquaculture section comes under the main heading 'Productive', which is more descriptive of the nature of the surrounding sea than the land-based 'Business and Industry' of the previous editions; this symbolically slips the plan into the geographical setting of its concerns. Also, the content of the aquaculture section has been revised and expanded, with, for example, more statistics on the economic importance of the industry and more subtle improvements of explanatory text. So striated and smooth manners of progression are at work, lending their force to produce either clear demarcation or gradual progression in relation to the preceding version.

The policies presented in Edition 4 overlap with the previous ones, but with some significant changes. The policies on key conditions and management plans remain, though with some rewording. The policy on separation distances is replaced by one on development management plans. This suggests a more flexible approach to achieving a reduction in environmental impacts, such as on protected habitats, and an improvement in community benefits, such as reduced visual impact; the onus is on applicants to come up with holistic solutions that bring about a range of benefits.
Perhaps most importantly, there is a completely new policy on seaweed cultivation, favouring applications for its development, especially using species native to Shetland. This is in a whole new sub-section supporting the establishment of this industry alongside existing forms of aquaculture. Information is also provided, again for the first time, on integrated multitrophic aquaculture: the co-location of finfish, shellfish and seaweed, so that the wastes produced by the finfish are used as nutrients by the shellfish (taking up the organic waste) and seaweed (taking up the inorganic waste). This is seen as holding potential for better use of resources and reduction of environmental impact; however, Edition 4 does not go so far as introducing a policy to support its uptake. Similarly along forward-looking lines is the possibility that advancing technology will allow aquaculture to move away from the voes into offshore areas. So a logic of step change is added to that of the incremental growth that has driven policy development throughout the process, with the suggestion of further strides as the process continues. All the while, however, progress is being more finely shaped by industry initiatives and sitespecific considerations.

The sequence of maps through the MSP process also reveals progression of the two spatial types. Firstly, there is a trend to greater accuracy in portraying the location of existing aquaculture sites. Editions 1 and 2 have maps indicating the location of existing finfish and shellfish areas, showing their wide dispersal around the islands (Fig. 3). These are represented as regular 2-km grid squares, colour-coded to represent a simple, stepped increase of intensity. In Edition 3, the maps change to show the sites more simply, as small squares for individual sites, without any impression of 'intensity' other than the number of squares in given areas (Fig. 4). These squares are clearly not to scale, though they imply a desire to show with more precision the areas occupied, an attempt, perhaps, at greater striation in the representation of aquaculture. Edition 4 shows the sites even more tightly, by presenting them as polygons that are approximately to scale, to the point that the smallest ones are difficult to see. Secondly, and very significantly, there is a growing concern in the maps to encourage future development; here, more expansive and open representations are used. This is implied in the intensity mapping of Editions 1 and 2, the steer presumably being towards areas of low intensity. But this becomes much stronger in Edition 4, where explicit 'locational guidelines' are provided. This includes large 'restricted areas', but also whole voes that are categorised according to their potential, with some offering the 'best prospects of expansion' in a zoomed-in version of the map (Fig. 5). Potential developers are thus invited to roam smoothly within broadly defined areas to find their preferred spots. It is noteworthy that even at the slightly more strategic scale of planning represented by these maps, both manners of operation are at work, with smooth explorations permitted within clearly bounded areas. 


\section{MAP 3}

AQUACULTURE: USE INTENSITY OF FIN FISH FARMING

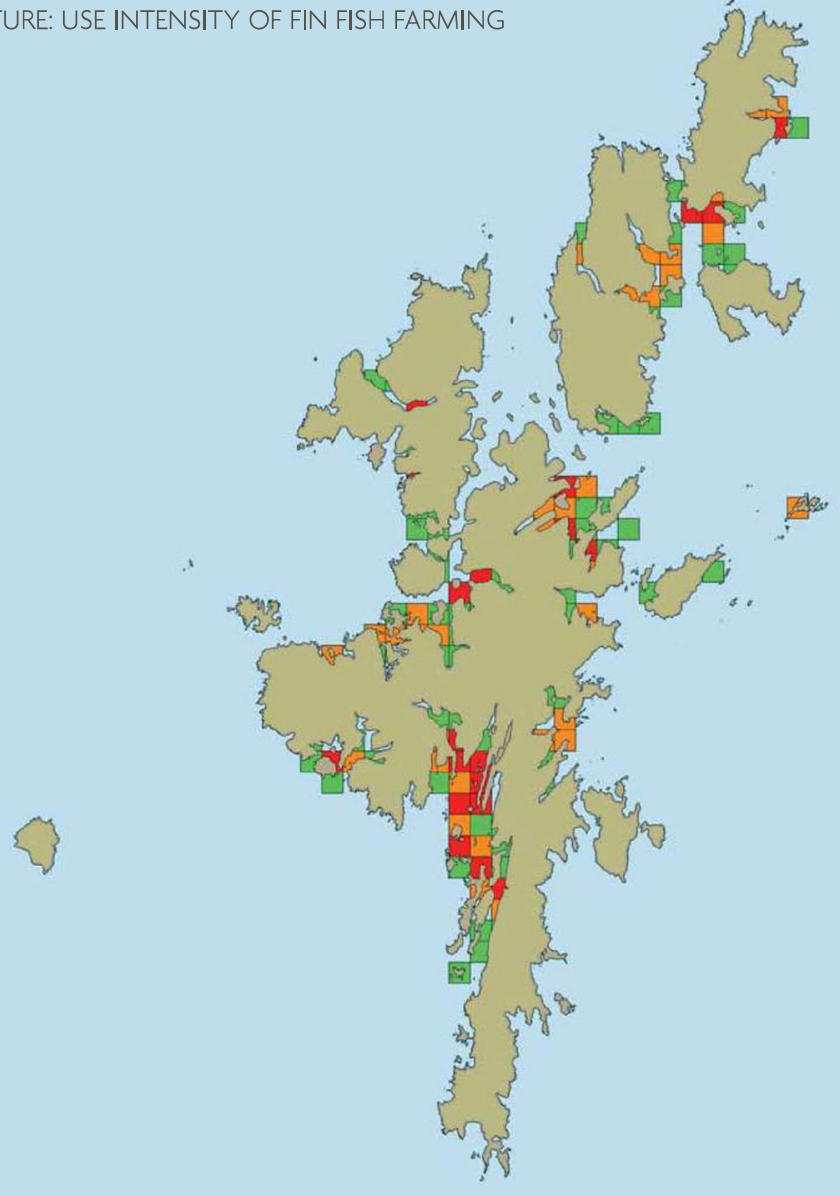

1

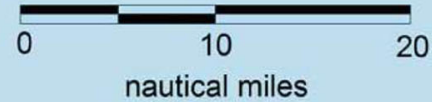

$\left\{\begin{array}{l}\xi^{2} \\ y^{2}\end{array}\right.$

Fin Fish Farming Intensity (in $2 \mathrm{~km}$ grid squares)

Low
Moderate
High

Fig. 3 Finfish aquaculture areas, Shetland, Edition 1 (@ NAFC Marine Centre UHI)
Original Data Source: Shetland Islands Council and Lerwick Port Authority

(c) Crown Copyright. All rights reserved (2007). 
MAP 3

AQUACULTURE: USE INTENSITY OF FIN FISH FARMING
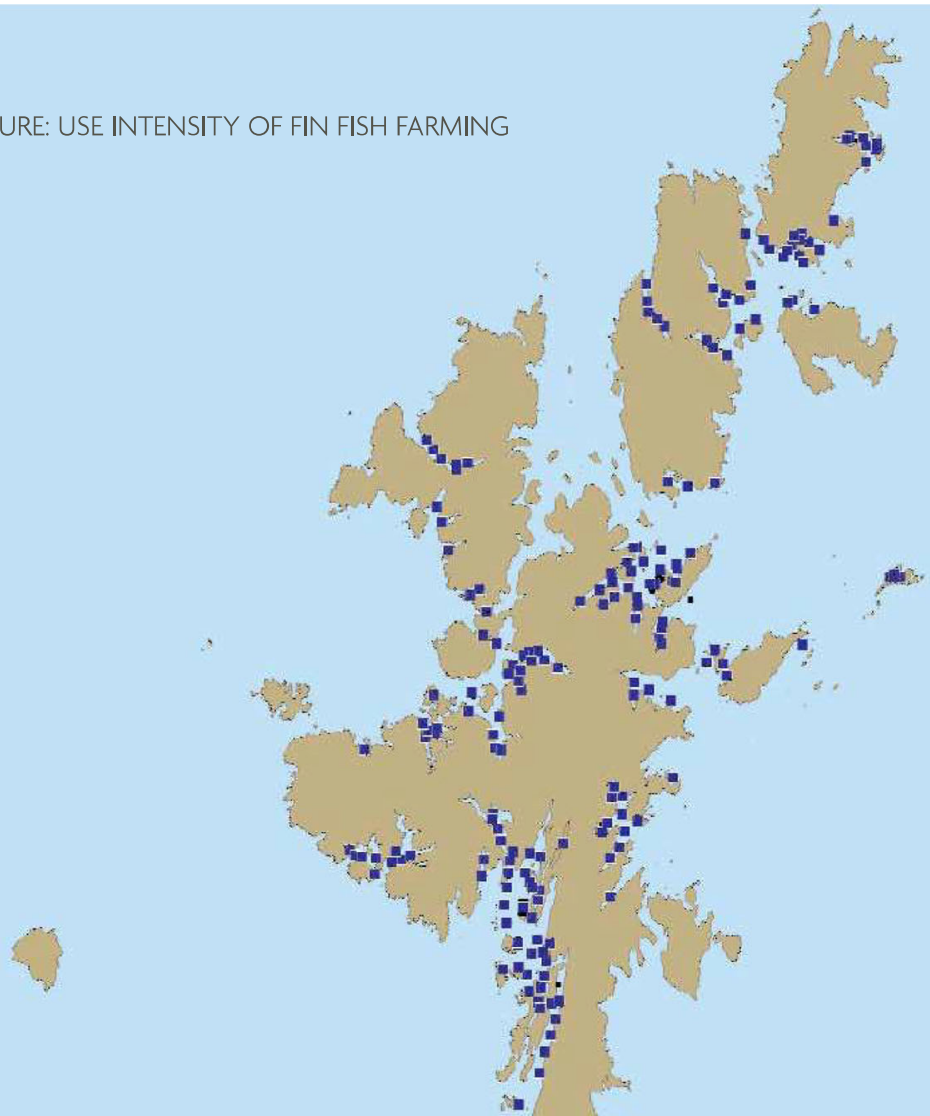

in

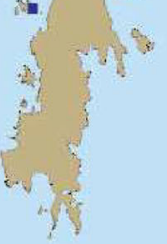

4

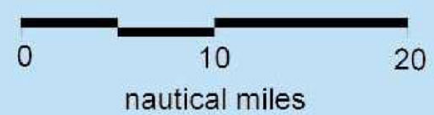

Fin Fish Site

Original Data Source: Shetland Islands Council and Lerwick Port Authority

Reproduced by permission of Ordnance Survey on behalf of HMSO. () Crown copyright and database right 2010. All rights reserved. Ordnance Survey Licence number 100024344.

Fig. 4 Finfish aquaculture areas, Shetland, Edition 3 (@ NAFC Marine Centre UHI) 


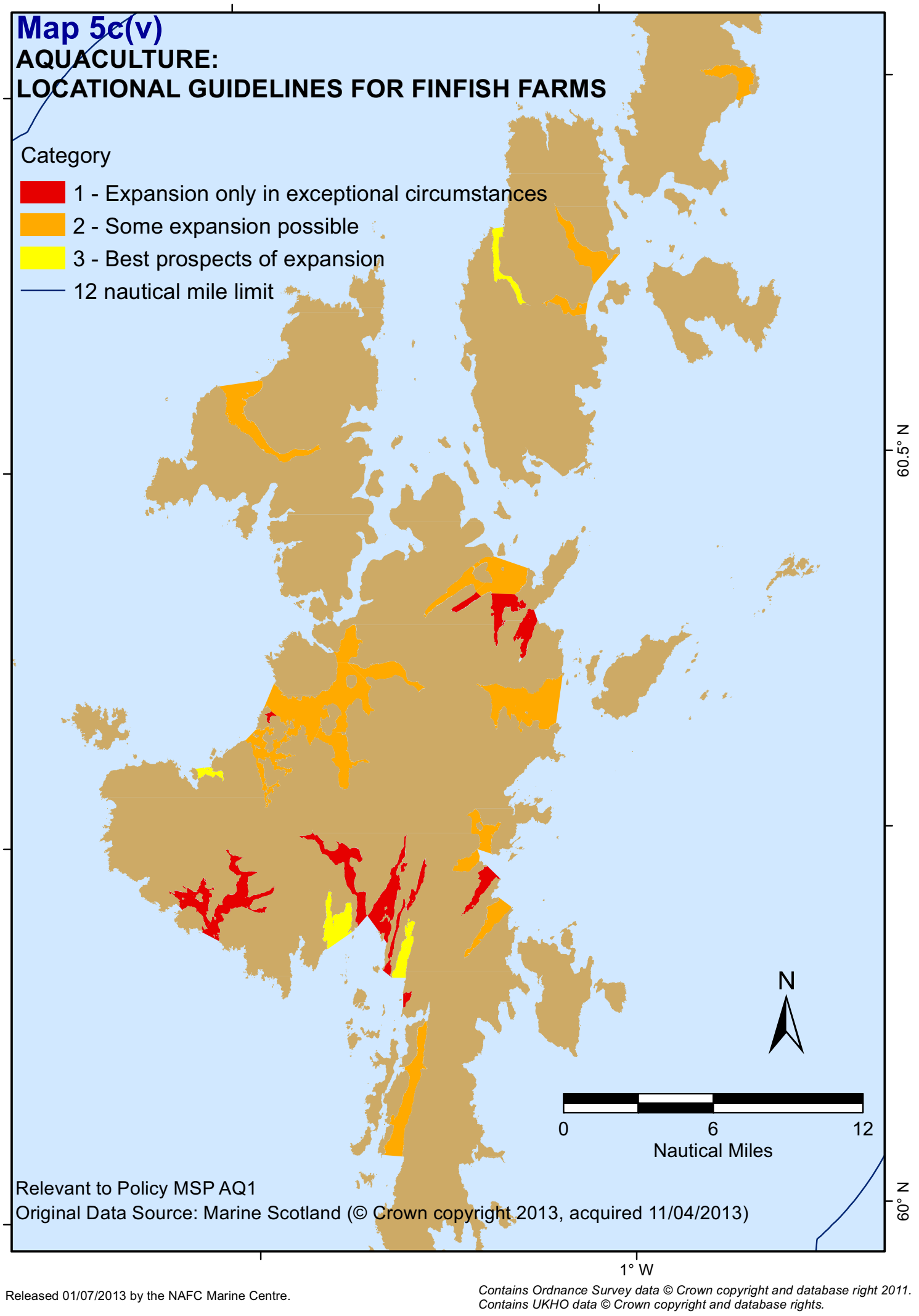

Fig. 5 Finfish aquaculture potential, Shetland, Edition 4 (@ NAFC Marine Centre UHI) 
To summarise, all of the documents are suffused with striated and smooth spatialities, performing different and complementary roles. The work performed by the former is largely that of setting conditions for development expressed in quantitative or rule-based terms. The latter works by bringing discretionary judgements into play, in the form of statements that allow for possibilities. One type frequently leads to or gives way to the other, as if neither is sufficient by itself. It is by this oscillation that the aquaculture policy emerges and proceeds at each stage. A frequent mechanism is that striations set parameters within which smoother movements can take place, and possibly override them.

Looking also at the sequence of documents, both spatialities are at work. Firstly, the geometric advance of Editions suggests control being increasingly asserted; this begins with Editions 1 and 2 placing emphasis on channelling development into acceptable locations, followed by Edition 3 setting out some blanket restrictions, and culminates in Edition 4 attaining statutory weight. Secondly, these top-down measures are tempered by the room for manoeuvre that emerges during the process, through possible exceptions to the rules and reasoned interventions; this leads, for example, to the encouragement of tailored, industry-led management plans in Edition 3, which are developed further in Edition 4. Thirdly, the two forces come together in the increasingly forward-looking perspective of the process. This is illustrated by the maps, where the emphasis shifts to pointing to suitable areas for development, and in the ambitions of Edition 4 for seaweed cultivation and integrated multi-trophic aquaculture. These involve both step changes and driving vectors, an interdependence of steady progress and visionary becoming, the two embracing in one productive process. Finally, in all of this, policy progression is bound to the physical development of aquaculture itself. For example, more open provisions are made as opportunities for new development emerge. There is a textual-material alliance by which policy and industry are exerting their efforts together and shaping one another: as the industry presses for more opportunities, in terms of growth and technological innovation, planners respond with development criteria and a steer towards preferred areas, and by encouraging industry to take good practice initiatives. In all of this, the temporally driven nature of this endeavour is evident, as industry and planning continue to respond to the results of their own co-working. This study therefore illustrates the more experimental and gradual nature of plan-making than suggested by rational understandings, with the options available from striated and smooth manners of working being variously called upon and used to balance and build upon each other. Arguably, the marine setting, with its natural dynamism and more tenuous human relationship with it, intensifies the need for more agile approaches of this kind.

\section{Spatial production and progress}

In the introduction to this article, I suggested that there is now an opportunity to explore how MSP processes have developed over time, with a view to understanding how authorities are evolving in their planning interventions. I also suggested that instead of placing this in the context of adaptive management, which is rather procedural in nature, it would be better to turn to a framework that can be more ontologically immersed in the substance of MSP, that is to say set in the material and social concerns of MSP and the institutional process of plan-making (these two aspects being intertwined). Hence my choice of a body of thought that is spatial in the fullest sense, as it expresses this combining of object and process. This spatiality allows for investigation of progress, as it is embodies movement and change as well as occupation.

The striated-smooth model has been revealing. Used to interpret the development of aquaculture policy in the Shetland MSP process, it has shown how policy can progress both within any given stage and from one stage to the next by the interaction of these two spatial dynamics. In more conventional planning terms, these might broadly be described as forms of, on the one hand, regulation, development criteria, restriction and requirement, and, on the other hand, discretion, accommodation, negotiation and opportunity. They constantly call on each other, each acknowledging its limitations and need of the other, alternately advancing with different types of movement. Occasionally, they join forces in making significant shifts forward. Together therefore, they enable the MSP process to advance through different stages, gaining in confidence and setting out greater ambitions as it does so. These dynamics are evident in the policy text and maps, reflecting the manner of growth of the industry itself and its interaction with its environment. Enticingly, they also reproduce the materiality of the marine setting.

This example could indicate that similar dynamics are at work in other MSP processes. If the model can describe this multiplicity, it can describe others, too, and connect them together. However, the expression of these spatialities will vary. For example, the language above of regulation and discretion is reminiscent of discussion about the particularities of the UK tradition of planning (Booth 2003), which the Shetland MSP process may well be reflecting. Other MSP processes will involve their own means of striated and smooth working, reflecting, for example, different systems and scales of planning. But inherent in all working will be movement. This might mean, as in the case of Shetland, advancing towards greater assertion and steering activities more confidently; in other cases, it could mean retraction of one agenda, particularly if another gains ground. Progression is not inevitable; spatial production and interchange are. Researchers and practitioners could usefully consider how this spatiality may play 
out in other contexts, and the extent to which it may clarify the workings of an MSP process.

Purcell (2013) has called for the planning world to engage much more with Deleuze and Guatarri. He points to the breadth and richness of their work, in particular its radical political implications, which, he claims, challenge the very notion of stateled planning in favour of emergent organisation beyond the state. He considers striated space to be that of the capitalist state, including organised planning, while smooth space is that occupied by 'nomadic elements whose purpose is to destroy the state' ( $p$ 30). He prefers the latter, and looks for positive examples to support his case (Purcell and Born 2016).

But my reading of Deleuze and Guatarri's central chapter on the topic is that, almost throughout the whole text, no side is taken, and the authors content themselves simply with describing how (all) things work, with spatial dialectic at the core. And my microanalysis of policy formation suggests that, even if in the service of capitalism, planning proceeds as much by smooth working as by striated. Indeed, how could it be otherwise, if the two archetypes are necessarily at the heart of all spatial endeavour? This must hold true within all operations and at all levels. So the people engaged in MSP must have striated and smooth moments and movements within their own thinking and spatial productions. They must be attuned to the same dynamics within the material world of their concerns and be expressing similar energies and corresponding to its urges in their own institutions and outputs (Bennett 2004). They may wish to reflect on their own abilities to perform striated and smooth ways of thinking and acting. They may thus find a comfortable association with the industrious interaction of striated and smooth spaces in the natural and human structures and dynamisms of the coasts and seas, and add their efforts to producing a material-socialcognitive working system that advances its own goals from one movement to the next.

\section{Compliance with ethical standards}

Conflict of interest The author declares that he has no conflict of interest.

Open Access This article is distributed under the terms of the Creative Commons Attribution 4.0 International License (http:// creativecommons.org/licenses/by/4.0/), which permits unrestricted use, distribution, and reproduction in any medium, provided you give appropriate credit to the original author(s) and the source, provide a link to the Creative Commons license, and indicate if changes were made.

\section{References}

Abrahams, G. 2017. Making use of Deleuze in planning: proposals for a speculative and immanent assessment method. London: Routledge.

Agardy, T. 2010. Ocean zoning: making marine management more effective. London: Earthscan.
Allmendinger, P., M. Tewdwr-Jones, J. Knieling, and F. Othengrafen, eds. 2015. Soft spaces in Europe: re-negotiating governance, boundaries and borders. London: Routledge $248 \mathrm{pp}$.

Anderson, J., and K. Peters, eds. 2014. Water worlds: human geographies of the ocean. London: Routledge $196 \mathrm{pp}$.

Bennett, J. 2004. The force of things: steps toward an ecology of matter. Political Theory 32 (3): 347-372.

Blau, J., and L. Green. 2015. Assessing the impact of a new approach to ocean management: evidence to date from five ocean plans. Marine Policy 56: 1-8.

Bonta, M., and J. Protevi. 2004. Deleuze and geophilosophy: a guide and glossary. Edinburgh: Edinburgh University Press.

Booth, P. 2003. Planning by consent: the origins and nature of British development control. London: Routledge.

Bowen, G. 2009. Document analysis as a qualitative research method. Qualitative Research Journal 9 (2): 27-40.

Day, J. 2008. The need and practice of monitoring, evaluating and adapting marine planning and management: lessons from the Great Barrier Reef. Marine Policy 32 (5): 823-831.

DeLanda, M. 2002. Intensive science and virtual philosophy, 228 pp. London: Continuum.

Deleuze, G., and F. Guatarri. 1988. A Thousand Plateaus: capitalism and schizophrenia. London: Athlone Press.

Douvere, F., and C. Ehler. 2011. The importance of monitoring and evaluation in adaptive maritime spatial planning. Journal of Coastal Conservation 15: 305-311.

Dovey, K., and K. Polakit. 2010. Urban slippage: smooth and striated streetscapes in Bangkok. In Becoming Places: Urbanism/ Architecture/Identity/Power, ed. K. Dovey, 167-184. London: Routledge.

Ehler, C. 2014. A guide to evaluating marine spatial plans. Paris: UNESCO.

English Nature. (2003). Review of how the land use planning system could influence the development of a marine spatial planning system for England, English Nature Research Report 566, English Nature, Peterborough.

Haar, C., and J. Kayden, eds. 1989. Zoning and the American dream: promises still to keep. Chicago: Planners Press.

Haughton, G., P. Allmendinger, D. Counsell, and G. Vigar. 2010. The new spatial planning: territorial management with soft spaces and fuzzy boundaries. London: Routledge.

Healey, P. 2004. The treatment of space and place in the new strategic spatial planning in Europe. International Journal of Urban and Regional Research 28 (1): 45-67.

Hillier, J. 2007. Stretching beyond the horizon: a multiplanar theory of spatial planning and governance. Aldershot: Ashgate.

Hillier, J. 2010. Strategic navigation in an ocean of theoretical and practice complexity. In The Ashgate research companion to planning theory, ed. J. Hillier and P. Healey, 447-480. Aldershot: Ashgate.

Hull, A. 2013. Managing competition for marine space using the tools of planning in the UK. Planning Practice \& Research 28 (5): 503-526.

Jay, S. 2010. Built at Sea: Marine management and the construction of marine spatial planning. Town Planning Review 81 (2): 173-191.

Jay, S. 2012. Marine space: manoeuvring towards a relational understanding. Journal of Environmental Policy and Planning 14 (1): 81-96.

Jay, S. 2013. From disunited sectors to disjointed segments? Questioning the functional zoning of the seas. Planning Theory and Practice 14 (4): 509-525.

Jay, S. 2018. The shifting sea: from soft space to lively space. Journal of Environmental Policy and Planning 20 (4): 450-467.

Jay, S., T. Klenke, F. Ahlhorn, and H. Ritchie. 2012. Early European experience in marine spatial planning: planning the German exclusive economic zone. European Planning Studies 20 (12): 2013 2031. 
Kelly, C., L. Gray, R. Shucksmith, and J. Tweddle. 2014. Review and evaluation of marine spatial planning in the Shetland Islands. Marine Policy 46: 152-160.

Knol, M. 2011. Mapping ocean governance: from ecological values to policy instrumentation. Journal of Environmental Planning and Management 54 (7): 979-995.

Lefebvre, H. 1991. The production of space. Oxford: Blackwell.

Livesey, G. 2010. Space + Architecture. In The Deleuze dictionary, 2nd ed, ed. A. Parr, 262-264. Edinburgh: Edinburgh University Press.

Lysen, F., and P. Pisters. 2012. Introduction: the smooth and the striated. Deleuze Studies 6 (1): 1-5.

Massey, D. 2005. For space. London: Sage.

May, T. 2011. Social research: issues, methods and process. 4th ed. Buckingham: Open University Press 332 pp.

McGregor, D., D. Simon, and D. Thompson, eds. 2006. The peri-urban interface: approaches to sustainable natural and human resource use. London: Earthscan $336 \mathrm{pp}$.

NAFC Marine Centre. 2010. A marine spatial plan for the Shetland islands: third edition. Scalloway: NAFC Marine Centre.

Purcell, M. 2013. A new land: Deleuze and Guatarri and planning. Planning Theory \& Practice 14 (1): 20-38.

Purcell, M. \& Born, B. (2016). Planning in the spirit of Deleuze and Guatarri? Considering community-based food projects in the United States and Mexico, Urban Geography, pp. 1938-2847.

Scottish Government. 2008. Sustainable seas for all: a consultation on Scotland's first marine bill. Edinburgh: Scottish Government.

Scottish Government. (online). Shetland isles marine planning partnership, https://www2.gov.scot/Topics/marine/seamanagement/ regional/partnerships/Shetland (accessed 01/10/19).

Scottish Sustainable Marine Environment Initiative (SSMEI). 2008. A marine spatial plan for the Shetland Islands. Scalloway: NAFC Marine Centre.
Scottish Sustainable Marine Environment Initiative (SSMEI). 2009. A marine spatial plan for the Shetland Islands. Scalloway: NAFC Marine Centre.

Shetland Islands Council (SIC). 2007. Interim policy for marine aquaculture. Lerwick: SIC.

Shetland Islands Council (SIC). 2014a. Shetland in statistics 2014. Lerwick: SIC.

Shetland Islands Council (SIC). 2014b. Supplementary guidance: Shetland Islands' marine spatial plan: fourth edition 2014. Lerwick: SIC.

Shetland Islands Council (SIC). 2017. Shetland in statistics: 2015 and 2016. Lerwick: SIC.

Slater, A. 2004. 'Land use' planning for Scotland's marine environment? Journal of Water Law 15 (2): 49-54.

Soja, E. 1996. Thirdspace: journeys to Los Angeles and other real-andimagined places. Oxford: Blackwell.

Stake, R. 1998. Case Studies. In Strategies of qualitative inquiry, ed. N. Denzin and Y. Lincoln, 86-109. London: Sage Publications.

Tyldesley, D. (2004) Making the case for marine spatial planning in Scotland, report commissioned by RSPB Scotland and RTPI in Scotland, unpublished document

UNEP \& GEF-STAP. (2014). Marine spatial planning in practice: transitioning from planning to implementation, UNEP, Nairobi Available at: https://www.cbd.int/doc/meetings/sbstta/sbstta-18/ information/sbstta-18-inf-23-en.pdf (accessed 01/10/19).

Publisher's note Springer Nature remains neutral with regard to jurisdictional claims in published maps and institutional affiliations. 